\title{
PADRÕES HOMOGÊNEOS DE INSOLAÇÃO NO RIO GRANDE DO NORTE
}

\author{
Samira de Azevedo Santos ${ }^{1,3, *}$, Pollyanna Kelly de Oliveira Silva ${ }^{1,4}$, Magaly de Fatima \\ Correia $^{2}$, Maria Regina da Silva Aragão ${ }^{2}$ \\ ${ }^{1}$ PPG em Meteorologia/CTRN/UFCG, Campina Grande, PB, Brasil \\ ${ }^{2}$ DCA/CTRN/UFCG, Campina Grande, PB, Brasil \\ ${ }^{3}$ CTGÁS-ER, Natal, RN, Brasil \\ ${ }^{4}$ IMPSA, Cabo de Santo Agostinho, PE, Brasil \\ *samira.azevedo@yahoo.com.br
}

\section{INTRODUÇÃO}

Atualmente, vem despontando um crescente incentivo ao uso de fontes de energia limpas, onde os danos ao meio ambiente são minimizados e constitui-se uma forma alternativa e complementar aos procedimentos de geração de energia elétrica usuais. Assim, as fontes de energia renováveis como a solar e a eólica estão, cada vez mais, sendo necessárias, utilizadas e desenvolvidas. A energia solar tem por característica uma elevada variabilidade temporal e essa variabilidade está associada a padrões meteorológicos atuantes.

Visando identificar padrões de variabilidade temporal entre os elementos meteorológicos e os níveis de insolação no estado do Rio Grande do Norte (RN), foi aplicada a análise de agrupamento (AA), com o intuito de promover a identificação e compreensão dos processos físicos envolvidos nas diversas escalas de tempo. Assim, este trabalho procurou determinar a variabilidade sazonal da insolação no $\mathrm{RN}$, utilizando dados diários de insolação coletados em seis estações meteorológicas no período de 2003 a 2012.

\section{MATERIAL E MÉTODOS}

Foram analisados dados diários de insolação coletados por heliógrafos de 6 estações do Instituto Nacional de Meteorologia (INMET) situadas no RN referentes ao período de 2003 a 2007, totalizando 10 anos de medições. Os meses de junho e novembro foram escolhidos como representativos do período seco e úmido respectivamente. As estações analisadas foram: Apodi, Caicó, Ceará Mirim, Cruzeta, Florânia e Natal.

A AA foi realizada utilizando o método de classificação hierárquica de Ward, cuja medida de similaridade usada foi a distância euclidiana quadrada, recomendada para os métodos de agrupamento centróide e de Ward. A distância euclidiana quadrática é obtida pela equação (1):

$$
d_{i j}^{2}=\sum_{v=1}^{p}\left(x_{i v}-x_{j v}\right)^{2}
$$

onde $v$ são as variáveis $(v=1,2,3, \ldots, p) ; x_{i v}$ é a $v$-ésima característica da $i$-ésima observação e $x_{j v}$ é a $v$-ésima característica da $j$-ésima observação. 
O critério de agrupamento utilizado no trabalho é o proposto por WARD (1963). Como input foi usado o modo de análise de variáveis espacial ou Modo S (RICHMAN \& LAMB, 1985). Neste modo é avaliada apenas uma variável (insolação) estando os dados dispostos conjuntamente sob a forma de matriz, onde cada $n$ linha corresponde aos dados de um único mês para todos os anos, e as $p$ colunas às estações. $\mathrm{O}$ objetivo nesse tipo de análise é identificar padrões climáticos específicos.

\section{RESULTADOS E DISCUSSÕES}

No mês de junho (Figura 1a) o Grupo I foi formado pelos anos de 2004 e 2005, que é caracterizado pelos menores índices de insolação. O mês de junho é caracterizado como o período de maior atuação dos Distúrbios Ondulatórios de Leste - DOL. São distúrbios que se propagam para oeste na área dos ventos alísios, apresentando configurações ondulatórias nos campos de vento e pressão e dentre outras características, provoca o aumento de nebulosidade. Segundo o Boletim Climanálise, nos anos de 2004 e 2005, a formação de aglomerados de nuvens associados à propagação de distúrbios de leste e a atuação da alta pressão subtropical do Atlântico Sul foram favoráveis à ocorrência de bastante convecção o que ocasionou chuvas acima da média histórica no litoral do Nordeste, desde o Ceará até o norte de Sergipe. O grupo II foi composto pelos anos de 2006, 2007, 2008, 2009 e 2011, que é caracterizado pelos valores médios de insolação do período. O Grupo III agrupou os anos de 2003, 2010 e 2012, que tem como característica principal os maiores índices de insolação, esses anos são evidenciados por chuvas abaixo da média para o mês de junho no RN.

Nos resultados das análises para novembro, estação seca, sob o ponto de vista climatológico, o Grupo I foi formado pelos anos de 2007, 2008, 2010 e 2012. Valores máximos de insolação, com exceção das estações de Ceará Mirim e Natal constituiram a característica marcante do período. A proximidade destas estações com o Oceano Atlântico, faz com estejam sob o efeito das brisas. As brisas não são fenômenos exclusivos de tempo claro, elas afetam e interagem com vários tipos de nuvens. A diferença térmica entre a terra aquecida e o oceano mais frio aumenta ao longo do dia e a circulação da brisa se intensifica e pode ser identificada pela nebulosidade em forma de linha no período da tarde, aproximadamente paralela à costa e para dentro do continente. $\mathrm{O}$ segundo grupo foi formado pelos anos de 2003, 2004, 2005 e 2006 e teve como característica apresentar valores médios de insolação. O Grupo III, formado pelos anos de 2009 e 2011, teve por particularidade apresentar os menores valores do período. Nas Figuras 1e e 1f observa-se a variabilidade da insolação do mês de novembro ao longo do período e os valores médios de insolação dos grupos homogêneos.

\section{CONCLUSÕES}

A AA permitiu identificar 3 grupos homogêneos, o grupo dos máximos valores, o grupo dos valores médios e o grupo dos mínimos valores de insolação. Sendo a insolação inversamente proporcional a precipitação, os mínimos valores de insolação são encontrados quando a atmosfera está sob o efeito dos principais sistemas atmosféricos produtores de chuva da região. 


\section{REFERÊNCIAS}

WARD, J. H. Hierarchical grouping to optimize an objective function. Journal of the American Statistical Association. Alexandria, v.58, n.301, p.236-244, $1963 .$.

RICHMAN M. B.; LAMB P. J. Climatic Pattern-Analysis of 3-day and7-day Summer Rainfall in the Central United States - Some Methodological Considerations and a Regionalization. Journal of Climate and Applied Meteorology, v. 24 (12), p.1325-1343, 1985.

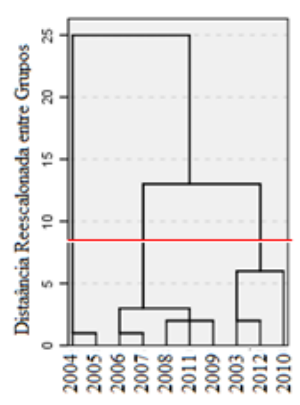

(a)

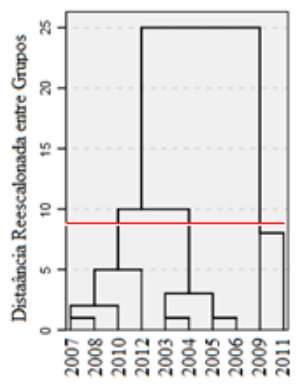

(d)

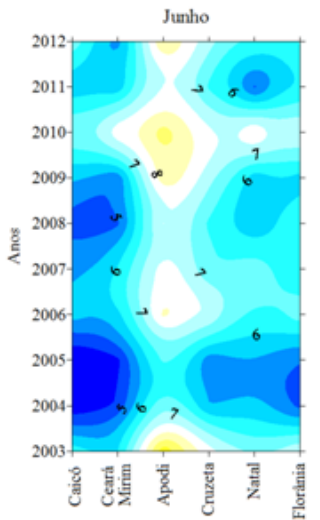

(b) Estaçes

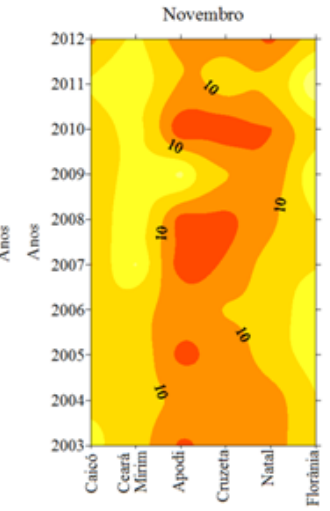

(e)
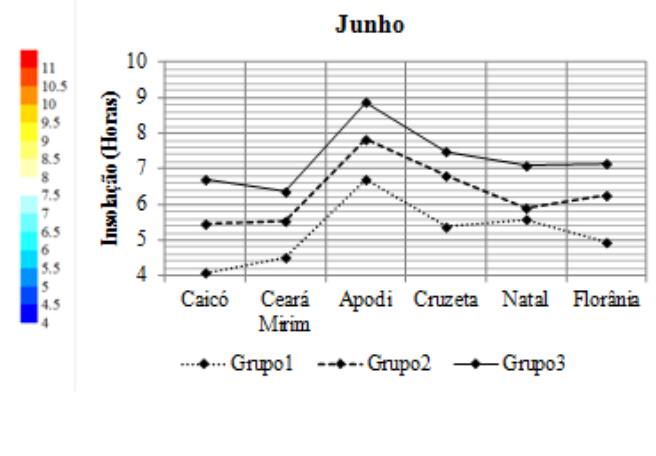

(c)

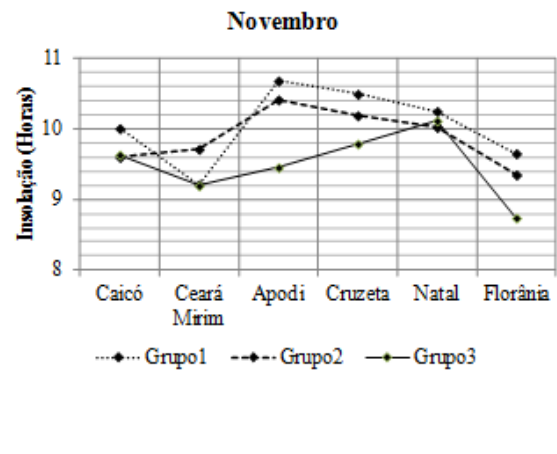

(f)

Figura1: Dendrograma da definição de anos homogêneos de (a) junho e (d) novembro, variabilidade média mensal da insolação para o período de 2003 a 2012, das seis estações meteorológicas do INMET de (b) junho e (e) novembro e insolação média dos grupos homogêneos formados na análise conjunta de (c) junho e (f) novembro. 